\title{
Aluminum-induced amyloidogenesis and impairment in the clearance of amyloid peptides from the central nervous system in Alzheimer's disease
}

\author{
Yuhai Zhao $^{1,2}$, James M. Hill ${ }^{1,2,3}$, Surjyadipta Bhattacharjee ${ }^{1}$, Maire E. Percy ${ }^{4,5,6}$, Aileen I. D. Pogue ${ }^{7}$ and \\ Walter J. Lukiw ${ }^{1,2,7,8 *}$
}

${ }^{1}$ LSU Neuroscience Center, Louisiana State University Health Sciences Center, Louisiana State University, New Orleans, LA, USA

2 Department of Ophthalmology, Louisiana State University Health Sciences Center, Louisiana State University, New Orleans, LA, USA

${ }^{3}$ Department of Microbiology, Louisiana State University Health Sciences Center, Louisiana State University, New Orleans, LA, USA

${ }^{4}$ Department of Physiology, University of Toronto, Toronto, ON, Canada

${ }^{5}$ Department of Obstetrics and Gynaecology, University of Toronto, Toronto, ON, Canada

${ }^{6}$ Neurogenetics Laboratory, Surrey Place Centre, Toronto, ON, Canada

7 Alchem Biotech, Toronto, ON, Canada

${ }^{8}$ Department of Neurology, Louisiana State University Health Sciences Center, New Orleans, LA, USA

${ }^{*}$ Correspondence: wlukiw@Isuhsc.edu

Edited by:

Christopher Ariel Shaw, University of British Columbia, Canada

Reviewed by:

J. R. Walton, University of New South Wales Faculty of Medicine, Australia

Keywords: amyloidogenesis, Alzheimer's disease, A 342 peptide monomers, phagocytosis, aluminum, TREM2

\section{OVERVIEW}

The membrane-integral beta-amyloid precursor protein ( $\beta A P P)$ is probably the most intensively studied brain cell protein in neurobiology. $\beta$ APP is processed by tandem beta-gamma secretase cleavage into 42 amino acid amyloid (A $\beta 42)$ peptides, whose progressive accumulation is one distinguishing feature of Alzheimer's disease (AD) neuropathology (1-3). While homeostatic amounts of $A \beta 42$ peptide generation and clearance seem to be tolerated by brain cells, their over-abundance, aggregation into higher order structures, and inability of brain cells to effectively phagocytose and clear these intensely hydrophobic peptides contribute to the pro-inflammatory and neurotoxic pathology of AD. Aluminum, as an extremely high charge density cation $\left(Z^{2} / r=18\right)$, has the remarkable capability to both (1) aggregate and compact $A \beta 42$ peptide monomers into higher order, more neurotoxic oligomeric, and fibrillar structures, and (2) impair, at the molecular-genetic level, the cellular machinery responsible for $A \beta 42$ peptide monomer phagocytosis and clearance from the cell (4-13). This opinion paper will briefly assess these two remarkable, functionally overlapping, and decidedly neurotoxic properties of aluminum: (1) on the ability of physiologically realistic amounts of aluminum to aggregate $A \beta 42$ peptide monomers into higher order dimeric, oligomeric, and fibrillar structures, and (2) on the ability of aluminum to impair at nanomolar concentrations and at the level of epigenetic regulation, microglial cell-mediated clearance mechanisms of $A \beta 42$ peptides from the extracellular space of the brain and CNS.

\section{ALUMINUM, A 442 PEPTIDES, AND AMYLOIDOGENESIS}

The polytopic transmembrane glycoprotein $\beta$ APP ( $~ 770$ amino acids), highly expressed in human neurons has been implicated as a regulator of neuronal cytoarchitecture, synaptic plasticity, axon guidance, and cell-cell interactions in the brain and retina (1-3). Via tandem beta-gamma secretase cleavage, $A \beta 42$ peptides are naturally generated as monomers from $\beta A P P$, however, due to their intensely lipophilic and hydrophobic character (21.4\% valine-isoleucine), $\mathrm{A} \beta 42$ monomers rapidly aggregate into higher order structures forming $A \beta 42$ dimers, oligomers, and fibrils to ultimately aggregate to form the core of the senile plaque lesions that in part characterize $\mathrm{AD}$ (13). Factors, which accelerate $A \beta 42$ peptide monomer aggregation, such as aluminum sulfate and other aluminum and metallic salts, apparently do so by cross-linking anionic amino acids contained within the 42 amino acid $A \beta 42$ peptide sequence, to form larger $A \beta 42$ peptide-containing "clumps" $(1,6)$. These roughly spherical deposits eventually form into dense, insoluble senile plaques $\sim 100 \mu \mathrm{m}$ or more in diameter that are often visible to the unaided eye after Congo Red or other suitable amyloid staining (2-6). A 342 peptide coalescence apparently occurs in much the same way as the aluminum in hydrated aluminum potassium sulfate [alum; $\mathrm{KAl}\left(\mathrm{SO}_{4}\right)_{2} \cdot 12 \mathrm{H}_{2} \mathrm{O}$ ], which is used worldwide as a clarifying agent in water purification, reacts with impurities. When added to turbid drinking water, aluminum crosslinks organic impurities, allowing them to flocculate or "stick together" and precipitate out of solution, resulting in a highly clarified and esthetically pleasing "finished" water product (14). Interestingly, aggregation of $\mathrm{A} \beta 42$ peptides into senile plaques can be visualized in the living brain using multi-photon in vivo imaging of transgenic mouse models of $\mathrm{AD}$, and can take as little as $24 \mathrm{~h}$ to form, a remarkably rapid time course in light of the fact that $\mathrm{AD}$ represents such a slowly progressing neurological disease with age-related amyloid deposition (15). In particular, interactions with biosphere-abundant, AD-relevant metal ions such as aluminum may lead to the formation of highly structured amyloid aggregates with peculiar biophysical properties that are associated with an extremely high degree of neurotoxicity $(3-6,16-20)$. 


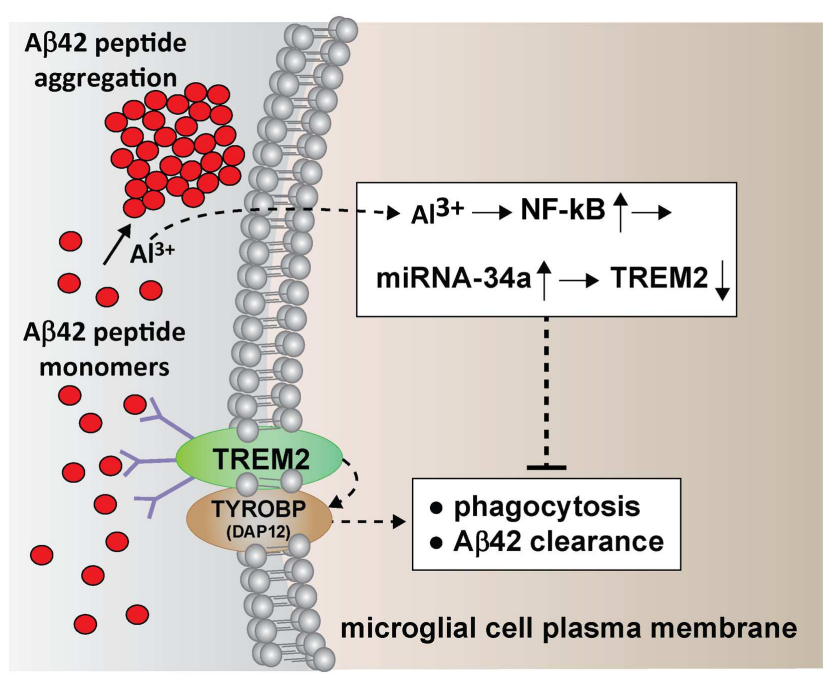

FIGURE 1 | Multiple neurotoxic actions of aluminum results in an impairment in the clearance of A342 peptides that drives amyloidogenesis and AD-type change; in intra-cellular and intra-nuclear compartments, aluminum induces NF-kB $(5,14,15)$, up-regulates miRNA-34a $(9,10)$, and down-regulates TREM2, a key microglial intra-membrane phagocytic sensor protein $(6-8,11)$; lack of sufficient TREM2 impairs microglial cell-mediated phagocytosis and clearance of $A \beta 42$ peptide monomers; deficits in TREM2 (but not the TREM2-associated TYROBP/DAP12 adaptor protein required for phagocytosis and $A \beta 42$ peptide engulfment) have been widely reported in $A D$ brain and in stressed microglial cells $(7,8,11)$; in the extracellular space (upper left) aluminum aggregates A $A 42$ peptide monomers into dense insoluble spherical clumps and promotes senile plaque formation; the movement of $\mathrm{Al} 3+$ across the plasma membrane is not well understood but may involve both active and passive transport; while microglia are able to phagocytose Aß42 peptide monomers that they may have difficulty with higher order aggregates resulting in microglial activation and a pathogenic pro-inflammatory response that contributes to AD neuropathology.

Aluminum's stimulatory effects on such AD-type neuropathology are further supported by the observation that transgenic murine models for $\mathrm{AD}(\mathrm{TgAD})$, such as the amyloid-overexpressing $\operatorname{Tg} 2576$ model, when fed aluminum in their diet, exhibit increased oxidative stress, proinflammatory signaling, and even more robust senile plaque lesion formation compared to non-aluminum fed TgAD controls $(21,22)$.

\section{ALUMINUM-MEDIATED \\ DOWN-REGULATION OF THE PHAGOCYTOSIS SENSOR PROTEIN TREM2}

Active microglial cell-mediated phagocytic processes that remove excessive, neurotoxic, or end-stage molecules from the brain are a naturally occurring mechanism to cleanse the neural environment and maintain neural homeostasis (711). Failure of these continuous homeostatic phagocytic processes has potential pro-inflammatory, innate-immune, and neuropathogenic consequences $(8-13,20)$. Interestingly, microglial cells, the "roving phagocytic scavengers" of the human brain and CNS surround aggregating $A \beta 42$ peptides and when so activated appear to play a role in inflammatory and immune aspects of $\mathrm{AD}$ pathogenesis including the further generation of brain cell-damaging reactive oxygen species (ROS) $(5,17-19)$. One key microglial transmembrane-spanning stimulatory sensor-receptor glycoprotein of the immune-globulin/lectin-like gene superfamily essential for phagocytosis of $\mathrm{A} \beta 42$ peptides in the brain and CNS is the inducible triggering receptor expressed in myeloid/microglial cells (TREM2; Figure 1) (7-13). This glycoprotein, an important player in the CNS innate-immune response extends molecular sensors into the extracellular environment to sense and recognize molecular tags located on $A \beta 42$ peptides - this is accomplished by poorly understood molecular-pattern recognition mechanisms (Figure 1) (10-13).
Aluminum sulfate, a known stimulator of ROS and the pro-inflammatory transcription factor NF-kB, is also known to induce a small family of pro-inflammatory microRNAs including miRNA-34a (712). An up-regulated miRNA-34a in turn down-regulates TREM2 expression in the microglial cell membrane leading to a deficit in the ability of microglial cells to effectively phagocytose $A \beta 42$ peptide monomers $(9,10,13)$. This ultimately results in a buildup of $A \beta 42$ peptides in the extracellular space, and thus favors their self-aggregation into higher order amyloid species (Figure 1).

Taken together, these results strongly suggest that one of the most prominent features of $\mathrm{AD}$ - the progressive accumulation and aggregation of $A \beta 42$ peptides into senile plaques - is driven by aluminum via multiple interdependent pathogenic mechanisms. These findings continue to support an active role for aluminum in key neuropathogenic, inflammatory, and amyloidogenic pathways that contribute to the $\mathrm{AD}$ process. Aluminum appears to therefore drive AD-relevant amyloidogenic pathology (1) directly, by aggregation of $\mathrm{A} \beta 42$ peptide monomers into higher order structures that subsequently form into senile plaque cores, and (2) indirectly, through an NF-kB- and miRNA-34a-mediated epigenetic mechanism that contributes to a down-regulation in the expression of the key phagocytosis sensor protein TREM2, and a failure of microglial cells to naturally sense, phagocytose, and eliminate neurotoxic A $\beta 42$ peptides. Hence, both of these pathways have strong potential to contribute, perhaps cooperatively, to the failure to adequately phagocytose naturally generated $A \beta 42$ peptide monomers, thus promoting their aggregation and driving amyloidogenesis with pro-inflammatory consequences. Indeed, the aluminum-mediated aggregation of $\mathrm{A} \beta 42$ peptide monomers into higher order structures of higher molecular mass may preclude them from being adequately "ingested" by microglial cellmediated phagocytic mechanisms, further supporting their accumulation and selfassociation in the extracellular space. It will certainly be interesting to see if aluminum salts perform similar pathogenic roles in other progressive, age-related neurodegenerative disorders of the CNS with 
an innate-immune, inflammatory, and/or amyloidogenic component.

\section{ACKNOWLEDGMENTS}

This research was presented in part at the Society for Neuroscience (SFN) Annual Meeting, San Diego, CA, USA, 9-13 November 2013. Research in the Lukiw laboratory on neurotoxic metals, microRNA, small non-coding RNA, the innate-immune response, amyloidogenesis, and neuroinflammation in $\mathrm{AD}$, retinal, and prion disease, was supported through a COBRE III Pilot Award, an unrestricted grant from Research to Prevent Blindness (RPB), the Louisiana Biotechnology Research Network (LBRN), and $\mathrm{NIH}$ grants NEI EY006311 and NIA AG038834.

\section{REFERENCES}

1. Zhang YW, Thompson R, Zhang H, Xu H. APP processing in Alzheimer's disease. Mol Brain (2011) 4:3-12. doi:10.1186/1756-6606-4-3

2. Alexandrov PN, Pogue A, Bhattacharjee S, Lukiw WJ. Retinal amyloid peptides and complement factor $\mathrm{H}$ in transgenic models of Alzheimer's disease. Neuroreport (2011) 22:623-7. doi:10.1097/WNR. 0b013e3283497334

3. Lukiw WJ. Amyloid beta $(A \beta)$ peptide modulators and other current treatment strategies for Alzheimer's disease (AD). Expert Opin Emerg Drugs (2012) 17(1):43-60. doi:10.1517/14728214. 2012.672559

4. Exley C. The aluminium-amyloid cascade hypothesis and Alzheimer's disease. Subcell Biochem (2005) 38:225-34. doi:10.1007/0-387-23226-5_11

5. Bolognin S, Zatta P, Lorenzetto E, Valenti MT, Buffelli M. $\beta$-amyloid-aluminum complex alters cytoskeletal stability and increases ROS production in cortical neurons. Neurochem Int (2013) 62:566-74. doi:10.1016/j.neuint.2013.02.008

6. Armstrong RA. Spatial correlations between betaamyloid (A $\beta$ ) deposits and blood vessels in familial Alzheimer's disease. Folia Neuropathol (2008) 46(4):241-8.
7. Fu R, Shen Q, Xu P, Luo JJ, Tang Y. Phagocytosis of microglia in the central nervous system diseases. Mol Neurobiol (2014) 49:1422-34. doi:10.1007/s12035-013-8620-6

8. Jones BM, Bhattacharjee S, Dua P, Hill JM, Zhao Y, Lukiw WJ. Regulating amyloidogenesis through the natural triggering receptor expressed in myeloid/microglial cells 2 (TREM2). Front Cell Neurosci (2014) 8:94. doi:10.3389/fncel.2014. 00094

9. Hickman SE, El Khoury J. TREM2 and the neuroimmunology of Alzheimer's disease. Biochem Pharmacol (2014) 88:495-8. doi:10.1016/j.bcp. 2013.11.021

10. Zhao Y, Bhattacharjee S, Jones BM, Dua P, Alexandrov PN, Hill JM, et al. Regulation of TREM2 expression by an NF- $\kappa$ B-sensitive miRNA-34a. Neuroreport (2013) 24:318-23. doi:10.1097/WNR. 0b013e32835fb6b0

11. Zhao Y, Lukiw WJ. TREM2 signaling, miRNA-34a and the extinction of phagocytosis. Front Cell Neurosci (2013) 7:131. doi:10.3389/fncel.2013.00131

12. Alexandrov PN, Zhao Y, Jones BM, Bhattacharjee S, Lukiw WJ. Expression of the phagocytosisessential protein TREM2 is down-regulated by an aluminum-induced miRNA-34a in a murine microglial cell line. J Inorg Biochem (2013) 128:267-9. doi:10.1016/j.jinorgbio.2013.05.010

13. Bhattacharjee S, Zhao Y, Lukiw WJ. Deficits in the miRNA-34a-regulated endogenous TREM2 phagocytosis sensor-receptor in Alzheimer's disease (AD); an update. Front Aging Neurosci (2014) 6:116. doi:10.3389/fnagi.2014.00116

14. Gopal K, Srivastava SB, Shukla S, Bersillon JL. Contaminants in drinking water and its mitigation using suitable adsorbents: an overview. J Environ Biol (2004) 25(4):469-75.

15. Spires-Jones TL, de Calignon A, Meyer-Luehmann M, Bacskai BJ, Hyman BT. Monitoring protein aggregation and toxicity in Alzheimer's disease mouse models using in vivo imaging. Methods (2011) 53:201-7. doi:10.1016/j.ymeth.2010.12.009

16. Campbell A, Becaria A, Lahiri DK, Sharman K, Bondy SC. Chronic exposure to aluminum in drinking water increases inflammatory parameters selectively in the brain. J Neurosci Res (2004) 75:565-72. doi:10.1002/jnr.10877

17. Bondy SC. Prolonged exposure to low levels of aluminum leads to changes associated with brain aging and neurodegeneration. Toxicology (2014) 315:1-7. doi:10.1016/j.tox.2013.10.008
18. Drago D, Bolognin S, Zatta P. Role of metal ions in the abeta oligomerization in Alzheimer's disease and in other neurological disorders. Curr Alzheimer Res (2008) 5:500-7. doi:10.2174/ 156720508786898479

19. Shcherbatykh I, Carpenter DO. The role of metals in the etiology of Alzheimer's disease. J Alzheimers Dis (2007) 11(2):191-205.

20. Koenigsknecht-Talboo J, Meyer-Luehmann M, Parsadanian M, Garcia-Alloza M, Finn MB, Hyman BT, et al. Rapid microglial response around amyloid pathology after systemic anti-A $\beta$ antibody administration in PDAPP mice. J Neurosci (2008) 28:14156-64. doi:10.1523/JNEUROSCI.4147-08. 2008

21. Praticò D, Uryu K, Sung S, Tang S, Trojanowski JQ, Lee VM. Aluminum modulates brain amyloidosis through oxidative stress in APP transgenic mice. FASEB J (2002) 16(9):1138-40.

22. Bhattacharjee S, Zhao Y, Hill JM, Percy ME, Lukiw WJ. Aluminum and its potential contribution to Alzheimer's disease (AD). Front Aging Neurosci (2014) 6:62. doi:10.3389/fnagi.2014.00062

Conflict of Interest Statement: The authors declare that the research was conducted in the absence of any commercial or financial relationships that could be construed as a potential conflict of interest.

Received: 29 July 2014; paper pending published: 14 August 2014; accepted: 20 August 2014; published online: 05 September 2014.

Citation: Zhao Y, Hill JM, Bhattacharjee S, Percy ME, Pogue AID and Lukiw WJ (2014) Aluminuminduced amyloidogenesis and impairment in the clearance of amyloid peptides from the central nervous system in Alzheimer's disease. Front. Neurol. 5:167. doi: 10.3389/fneur.2014.00167

This article was submitted to Neurodegeneration, a section of the journal Frontiers in Neurology.

Copyright (c) 2014 Zhao, Hill, Bhattacharjee, Percy, Pogue and Lukiw. This is an open-access article distributed under the terms of the Creative Commons Attribution License (CC BY). The use, distribution or reproduction in other forums is permitted, provided the original author(s) or licensor are credited and that the original publication in this journal is cited, in accordance with accepted academic practice. No use, distribution or reproduction is permitted which does not comply with these terms. 